\title{
Двухфононная релаксация состояний акцепторов бора в алмазе
}

\section{Бекин Н.А.}

ИФМ РАН, 603950, Нижний Новгород, ГСП-105

DOI 10.34077/Semicond2019-318

Теоретически исследуется релаксация дырок, находящихся в возбужденных состояниях акцепторов бора в алмазе, при испускании двух оптических фононов. Эта задача актуальна, поскольку энергия связи акцептора, 370 мэВ, более чем двукратно превышает максимальную энергию оптического фонона 165 мэВ. Для описания волновой функции акцепторных состояний использовался электроноподобный гамильтониан с изотропной эффективной массой. Волновая функция основного состояния находилась методом квантового дефекта. Для возбужденного состояния типа $2 p_{0}$ химический сдвиг игнорировался.

Вероятность перехода вычислялась в адиабатическом приближении. В этом подходе безызлучательные переходы рассматриваются как переходы, происходящие между собственными состояниями уравнения Борна - Оппенгеймера. Эти уравнения описывают стационарные состояния электрон-фононной системы, в которой взаимодействие между кристаллической решёткой и электроном, локализованным на примеси, является адиабатическим. Неадиабатическая часть взаимодействия решётки и электрона рассматривается как возмущение, которое вызывает переходы между этими состояниями, сопровождающиеся испусканием или поглощением одного или нескольких фононов. При этом вероятности таких процессов, в том числе многофононных, рассчитываются в первом порядке теории возмущений, в которой роль возмущения играет оператор неадиабатичности. Для матричных элементов этого оператора использовалось выражение [1], полученное в некондоновском приближении.

Значение деформационного потенциала, $D \approx 1.4 \cdot 10^{9}$ эВ/см, получено в результате подгонки к экспериментальным данным [2] по фактору Хуанга - Риса для уровней, соответствующих линии поглощения 304 мэВ в акцепторах бора. Такая процедура подгонки соответствует введению усредненной по зоне Бриллюэна константы электрон-фононной связи, которая учитывает сильную локализацию вовлеченных в переход состояний. Для сравнения, транспортные измерения в алмазе ртипа и их обработка методом Монте-Карло [3] дают величину деформационного потенциала для валентной зоны $2.1 \cdot 10^{9}$ эВ/см.

Закон дисперсии фононов считался изотропным, а частота фононов квадратично зависящей от модуля волнового вектора - с максимальным значением, достигаемым в центре зоны Бриллюэна ( $\hbar \omega_{\max }=165$ мэВ), и минимальным - на границе зоны Бриллюэна ( $\hbar \omega_{\min } \approx 147$ мэВ для LO фононов, $\hbar \omega_{\min } \approx 132$ мэВ для ТО фононов). Выявлена большая чувствительность вероятности перехода к характеристике дисперсии фононов, $\omega_{\max }-\omega_{\min }$, особенно для энергии перехода, $E_{T}$, в интервале $2 \hbar \omega_{\min }<E_{T}<\hbar \omega_{\min }+\hbar \omega_{\max }$. С этим связана большая чувствительность темпа двухфононной релаксации, $v$, для уровня с энергией связи 66 мэВ (энергия перехода 304 мэВ). Если в релаксацию дырок доминирует вклад LO фононов, то $v \approx 3 \cdot 10^{9} \mathrm{c}^{-1}$, если доминируют ТО фононы, $v \approx 6 \cdot 10^{11} \mathrm{c}^{-1}$. Если вклад всех типов оптических фононов сопоставим между собой, темп двухфононной релаксации имеет порядок $10^{11} \mathrm{c}^{-1}$.

Работа выполнена при финансовой поддержке РФФИ (грант №17-02-01325).

[1] Huang Kun, Scientia Sinica, 24, 27 (1981).

[2] G. Davies, R. Stedman, J. Phys. C: Solid State Phys., 20, 2119 (1987).

[3] L. Reggiani et al., Phys. Rev. B, 23, 3050 (1981). 